www.jmscr.igmpublication.org

Impact Factor 5.84

Index Copernicus Value: 83.27

ISSN (e)-2347-176x ISSN (p) 2455-0450

crossref DOI: _https://dx.doi.org/10.18535/jmscr/v5i7.52

Journal Of Medical Science And Clinical Research

\title{
A Study of Correlation between Carotid Intimal Medial Thickness and Left Ventricular Hypertrophy in Patients of Systemic Hypertension
}

Authors

\section{Dr Sunita Gupta MD, Dr Neha Mishra MD, Dr Ankit Gupta MBBS}

Dept of Medicine, Maharishi Markandeshwar Institute of Medical Sciences and Research Mullana, Ambala,

Haryana India

Corresponding Author

Dr Sunita Gupta

B2 Near Shiv Mandir, MMU Campus Mullana Ambala India

Email: sanjeevguptadr@gmail.com 91-9671023536

\begin{abstract}
Aim: To study carotid intima media thickness by Ultrasonography and establish diagnosis of left ventricular hypertrophy by echocardiography and electrogram, in patients of systemic hypertension. To correlate the findings of carotid ultrasonography with left ventricular hypertrophy.

Materials and Methods: The study was conducted at M.M. Institute of medical sciences and research, Mullana, Ambala. Fifty hypertensive patients with age <55years were taken from OPD and indoor wards of medicine department. According to JNC 7 criteria, stage 1 and stage 2 was considered for this study. B mode ultrasonography and $M$ mode 2 Dimensional echocardiography along with electrocardiogram were used to estimate the carotid intima medial thickness and left ventricular hypertrophy. The data obtained was subjected to appropriate statistical analysis for assuring the results of the study.

Result: There was appositive correlation between carotid intima media thickness and left ventricular hypertrophy.

Conclusion: Ultrasonography of carotids and 2D-Echocardiography should be performed in all patients of essential hypertension to so that early detection of cardiovascular and cerebrovascular complication of hypertension can be facilitated.
\end{abstract}

\section{INTRODUCTION}

Hypertension is a disease that effects whole body more or less. Complications of hypertension are related either to sustained elevations of blood pressure (with consequent changes in the vasculature and heart) or to Atherosclerosis that accompanies and is accelerated by long-standing hypertension. Cardiac complications are the major causes of morbidity and mortality in primary (essential) hypertension. ${ }^{1}$ Left ventricular hypertrophy may cause cardiac complications including congestive heart failure, ventricular arrhythmias, myocardial ischemia, and sudden death. Hypertension is the major predisposing cause of cerebrovascular complications like hemorrhagic and ischemic stroke. Chronic hypertension leads to nephrosclerosis, dissection of the aorta. ${ }^{1}$ and retinopathy 
In hypertension compliance of resistance of arteries \& vascular radius are important factors as resistance to flow varies inversely with the fourth power of the radius and hence as the lumen size decreases, resistance increases significantly. ${ }^{1}$ Remodelling refers to geometric changes in vessel wall without changing vessel volume(can be eutrophic or hypertrophic). The structural changes in vessel wall as hypertrophy and modification of extracellular matrix with the increase of collagen compound are main causes of arterial stiffness \& are related to raised blood pressure usually. It has been demonstrated that in progression of atherosclerosis, wall shear stress, that is frictional force produced by circulating blood column plays an important role. ${ }^{2}$ Atherosclerosis effects various regions of the circulation causes myocardial infarction, stroke and transient cerebral ischemia.. Intimal medial thickness can be measured on image of distal common carotid wall where echos from the intima media complex can be easily distinguished. As per the reporting done by certain authors it was seen that blood pressure levels are main determinants of intima media thickness while interaction of blood pressure with other (age) are more relevant for advanced intima media thickening ${ }^{1}$

Till date relationship between carotid atherosclerosis and left ventricular hypertrophy still disputable in case of hypertension. The main motive or aim of study is to evaluate, whether there is any association between carotid IMT values and left ventricular hypertrophy that can be detectable in hypertensive patients early. To fulfil this purpose only we have selected patients who are first diagnosed and are never treated for hypertension.

\section{METHODS AND MATERIAL}

The study was conducted at M.M. Institute of medical sciences and research, Mullana, Ambala. Fifty hypertensive patients with age < 55years was taken from OPD and indoor wards of medicine department. According to JNC 7 criteria, stage 1 and stage 2 were considered for this study. All patients were subjected to detail history after taking written and informed consent and detail systemic examination. Patients were excluded from the study those who were smokers, diabetic, past H/O- CAD/CKD/CVA/PVD/Secondary hypertension. Blood pressure in all studied subjects was recorded by using mercury sphygmomanometer. Two readings were taken at the same visit, in sitting position after giving a gap of 10-15 minutes and other necessary biochemical investigations were done.

\section{Carotid Ultrasonography}

The intimal medial thickness of Common carotid artery was determined by higher resolution B mode ultrasonography having a linear transducer with frequency $8 \mathrm{MHz}$. Scanning was done for 20 min. The intimal medial thickness was defined as distance from first echogenic line to second echogenic line. The first echogenic line represents lumen intimal interface \& second line was produced by collagen containing upper layer of intimal adventitia. The common carotid was visualized, and $1 \mathrm{~cm}$ proximal to the bifurcation of common carotid intimal medial thickness was measured. The total of 6 values was averaged to give mean CCIMT value for each patient. 2-D

\section{Echocardiography}

M-mode, two-dimensional and Doppler echocardiography examinations of the left ventricle was performed with subjects in the left decubitus position using an ultrasound system (model VIVID-E) with a $3.5 \mathrm{MHz}$ transducer frequency for M-Mode and $2.5 \mathrm{MHz}$ for Doppler recording. M-Mode tracings was quantified according to the recommendation of the American Society of Echocardiograph. Criteria for left ventricular hypertrophy was taken as:

- Left ventricular relative wall thickness $>0.45$. Relative wall thickness will be defined as posterior wall thickness + interventricular septal thickness / left ventricular interior dimensions Wall thickness of interventricular septum or posterior wall $>13 \mathrm{~mm}$ in diastole.

- Left ventricular mass index $>51 \mathrm{gm} / \mathrm{m}^{2.7}$. 
- The left ventricular mass was calculated by using the cube formula proposed by devereux ${ }^{3}$;

LV Mass = Myocardial volume x $1.05 \mathrm{~g} / \mathrm{cm}^{3}$ $=[(\text { IVS }+ \text { LVIDd }+ \text { PW })]^{3}-(\text { LVIDd })^{3} \times 1.05 \mathrm{~g} / \mathrm{cm}^{3}$

LV mass is corrected for height and body surface area and is taken as LV mass index.(gm x $\mathrm{m}^{2}$ ). It will be normalised for height ${ }^{2.7}$ to correct the effect of overweight. Left ventricular hypertrophy was defined as left ventricular mass index $>51 \mathrm{~g} / \mathrm{m}^{2.7}$

\section{OBSERVATIONS}

Fifty hypertensive patients with age <55years were taken from OPD and indoor wards of medicine department. According to JNC 7 criteria, stage 1 and stage 2 were considered for this study. Majority of the study patients $(86 \%)$ were in the age between 46-55 years. There were almost equal number of patients of either sex (M:F 24:26) 70\% of patients were in stage- 2 and $30 \%$ in stage- 1 of hypertension The Carotid intimal medial thickness was measured in all 50 patients on carotid Doppler study and according to the measurements obtained the study group was specifically analysed for CIMT values in these patients. The mean CIMT values were significantly higher in stage $2(0.86 \mathrm{~mm})$ as compared to stage $1(0.77 \mathrm{~mm})$ of hypertension. $\mathrm{p}=<0.05$ (statistical significant). $58 \%$ (29) patients had left ventricular hypertrophy (LVH). $42 \%(21)$ patients had no left ventricular hypertrophy (LVH).

The left ventricular hypertrophy was measured in all 50 patients, and according to the presence or absence of LVH the study group was divided into two. With LVH; total number of patients in this group was 29. Without $\mathrm{LVH}$; total number of patients in this group was 21. Patients with left ventricular hypertrophy had higher SBP corresponding to stage 2 that is $22(75.8 \%$ ) out of 29, stage 1- 7(24.13\%). The mean CIMT values were significantly higher $(0.917 \mathrm{~mm})$ in with $\mathrm{LVH}$ group as compared to $(0.704 \mathrm{~mm})$ in without $\mathrm{LVH}$ group. $\mathrm{P}=<0.0046$ (statistical significant).

Table-I Correlation of demographic and echocardiographic variables in two groups: Hypertensives with LVH and hypertensives without LVH.

\begin{tabular}{|l|c|c|c|}
\hline Variables & $\begin{array}{c}\text { Hypertensives with LVH } \\
(\mathrm{n}=29)\end{array}$ & $\begin{array}{c}\text { Hypertensives without } \\
\text { LVH }(\mathrm{n}=21)\end{array}$ & $\mathrm{p}$ value \\
\hline Age $($ Years $)$ & $50.96 \pm 6.02$ & $45.23 \pm 5.24$ & $<0.001$ \\
\hline Sex Male & $16(64 \%)$ & $9(36 \%)$ & \\
\hline Female & $13(52 \%)$ & $12(48 \%)$ & \\
\hline BMI $\left(\mathrm{Kg} / \mathrm{m}^{2}\right)$ & $24.6 \pm 4.18$ & $24.14 \pm 3.70$ & $>0.001$ \\
\hline SBP & $172.75 \pm 17.30$ & $151.52 \pm 10.42$ & $<0.001$ \\
\hline DBP & $104.27 \pm 7.28$ & $92.95 \pm 4.40$ & $<0.001$ \\
\hline IVSd $(\mathrm{cm})$ & $1.35 \pm 0.22$ & $0.91 \pm 0.20$ & $<0.001$ \\
\hline LVIDd $(\mathrm{cm})$ & $4.26 \pm 0.62$ & $3.68 \pm 0.73$ & $<0.001$ \\
\hline LVEF $(\%)$ & $62 \% \pm 4.25$ & $61 \% \pm 3.21$ & $>0.001$ \\
\hline LVMI $\left(\mathrm{gm} / \mathrm{h}^{2.7}\right)$ & $73.74 \pm 17.48$ & $38.0 \pm 9.44$ & $<0.001$ \\
\hline LVPWd $(\mathrm{cm})$ & $1.44 \pm 0.266$ & $1.02 \pm 0.25$ & $<0.001$ \\
\hline Mean CIMT $(\mathrm{mm})$ & $0.917 \pm 0.271$ & $0.704 \pm 0.217$ & $<0.0046$ \\
\hline
\end{tabular}

Table 1, shows that there was statistically significantly higher age in group of hypertensives with LVH as compared to hypertensives without LVH. However, there was no statistically significant difference between two groups in BMI ( $p=0.6890)$. The systolic blood pressure (SBP) and diastolic blood pressure (DBP) values were significantly higher in hypertensives with LVH as compared to hypertensives without LVH ( $\mathrm{p}<$
0.0001). IVSd, LVIDd, LVMI, LVPWd were significantly higher in hypertensive patients with LVH as compared to hypertensives without LVH. The mean CIMT values were significantly higher $(0.917 \mathrm{~mm})$ in with $\mathrm{LVH}$ group as compared to $(0.704 \mathrm{~mm})$ in without LVH group. $\mathrm{P}=<0.0046$ (statistical significant). 


\section{DISCUSSION}

This study was conducted among 50 hypertensive patients with age $<55$ years taken from OPD and indoor wards of medicine department.

The present study showed that almost equal number of hypertensive males and females were there in the study population, that is, 24 males and 26 females, with slight increased prevalence in females (52\%) when compared to males (48\%). The prevalence of hypertension was also observed to be increased with age as maximum number (86\%) of patients belonged to age group of 4655years. These findings were consistent with other studies done by Kokiwar PR et $\mathrm{al}^{4}$ DasSK et $\mathrm{al}^{5}$, Nitya Nand et $\mathrm{al}^{6}$, Lim TK et $\mathrm{al}^{7}$, Most of the patients in present study presented in the stage -II of hypertension according to the JNC criteria-7 (70\%) while rest $30 \%$ belonged to stage I. Gupta $\mathrm{R}$ et al also reported similar results in his study.

The data in present study showed that there was a positive correlation between CIMT and systolic blood pressure. The mean CIMT values were significantly higher in stage 2 as compared to stage 1 of hypertension ( $\mathrm{p}$ value <0.005). In various other studies similar findings were observed conducted by Nitya Nandet al ${ }^{6}$ Zanchetti $A$ et ${ }^{8}$ NityaNand et $\mathrm{al}^{6}$. In present study out of total 50 hypertensive patients $58 \%$ patients had left ventricular hypertrophy according to echocardiographic observations. While it was absent in the remainder $42 \%$, revealing high prevalence of left ventricular hypertrophy in the hypertensive patients.

The present study showed that there was a positive correlation seen between the carotid intima media thickness and left ventricular hypertrophy obtained by echocardiography. Out of 29 patients with LVH, the mean CIMT values were significantly higher $(0.917 \mathrm{~mm})$ in with $\mathrm{LVH}$ group as compared to $(0.704 \mathrm{~mm})$ in without $\mathrm{LVH}$ group. $\mathrm{P}=<0.0046$ (statistical significant). The other studies done by Cuspidi $\mathrm{C}$ et $\mathrm{al}^{9}$ Di Bello $\mathrm{V}$ et $a{ }^{10}$ Vaudo $G$ et $a{ }^{11}$ Parinello $G$ et $a l^{12}$. Thus there was altered pattern of left ventricular structure and carotid intimal medial thickness in large fraction of patients with essential hypertension. It's also evident that there occurs a very significant correlation between carotid intimal thickness and left ventricular hypertrophy. The probability of carotid thickness increases with higher stage of hypertension. CONCLUSION: We concluded that left ventricular hypertrophy and carotid intimal thickness was present in large number of patients with essential hypertension. It was also evident that there was a very significant co relation between carotid intimal thickness and left ventricular hypertrophy. The probability of carotid thickness increases with higher stage of hypertension. There were geometric and functional changes within common carotid artery in uncomplicated hypertension that parallel findings within the left ventricle. Ultrasonography for carotid intima media thickness along with 2D Echocardiography for left ventricle hypertrophy should be performed in all hypertensive patients, so that early detection of the risk factors for cerebrovascular and cardiovascular complication of hypertension is facilitated. This may give early warning for prevention of atherosclerosis at earlier stage in these patients

\section{REFRENCES}

1. Kotchen TA. Hypertensive vascular diseases: In Harrison's Principles of internal medicine. Kasper DL, Fauci AS, Longo DL, Braunwald E, Hauser SL, Jameson JL, editors. 17th ed. New York: McGraw Hill Companies;2008:1549-1562.

2. Poreds P.Intima- media thickness:indicator of cardiovascular risk and measureof extent of atherosclerosis .Sage Journal online.Vol.9(1):46-54,2004

3. Feigenbaum H. 2-Dimensional measurements In: Fiegenbaum's echocardiography. Fiegenbaum H, Armstrong WF, Ryan T, editors. $6^{\text {th }}$ edition;141-8, hypertension. Circulation. Vol.81:978-986, to the insulin resistance syndrome in elderly men. Circulation 2000,101:2595-2600. 
4. Kokiwar PR,Gupta SS.Prevalance of hypertension in a rural community of cental India.Int J Biol Med Res. 2011;(4): $50-3$

5. Das SK, Sanyal K, Basu. A study of urban community survey in india:growing trend of high prevalence of hypertension in a developing country. Int $\mathbf{J}$ Med Sci 2005;2(2):70-8

6. Nand N, Jain R, Seth S, Sen J, Sharma M. A New Marker of Carotid Athrosclerosis In Middle Aged Adults: Cystatin Cor Microalbuminuria. Indian Heart J, 2010;62:320-23

7. Lim TK, Lim E, Dwivedi G, Kooner J, Senior R. Normal value of caroti intimamedia thickness - a surrogate marker of atherscelrosis: quantative assessment by Bmode carotid ultrasound. J Am Soc Echocardiogr.2008 Feb;21(2):112-6

8. Zanchetti A, Crepaldi G, Bond MG, Gallus GV, Veglia F, Ventura A et al. Systolic and blood pressure (but not the diastolic blood pressure and seum cholesterol) are associated with alterations in carotid intima-media thickness in the moderately hypercholestrolaemic hypertensive patients of the Plaque Hypertension Lipid Lowering Italian Study. PHYLLIS Study group . J Hypertens. 2001 Jan;19(1):79-88

9. Cuspidi C, Lonati L, Macca G, Sampievi L, Fusi V, Michevi I, et al. Prevelance of left ventricular hypertrophy and carotid thickening in a large selected hypertensive population: impact of the different ecocardiographic and ultrasonographic diagnostic criteria. Blood Press. 2001:10(3):142-9

10. Di Bello V, Carerj S, Perticone F, Benedetto F, Palombo C, Talini E, et al. Carotid intima -media thickness in asymptomatic patients with aterial hypertension without clinical cardiovascular disease: realation with leftventricular geometry and mass and coexisting risk factors.Angiology.2009 Dec - 2010 Jan;60(6):705-13

11. Vaudo G, Schillaci G, Evangelista F, Pasqualini L, Verdecchia P,Mannarino E.Arterial wall thickeninig at different sites and its association with left ventricular hypertrophy in newly diagnosed essential hypertension. Am J Hypertens.2000 Apr;13(4):324-31

12. Parrinello G, Pinto A, Clomba D, Bologna P, Santolini R, Paterna $S$, et al. Relationship between left ventricular hypertrophy, diastolic function ad extracardiac atherosclrosi in newly diagnosed hypertensives. Am J Hypertens. 2001;14:162-3 